\title{
A mutation in the STAT1 DNA-binding domain associated with hemophagocytic lymphohistocytosis
}

\author{
Yoram Faitelson ${ }^{a *}$, Andrea Bates ${ }^{a}$, Manohar Shroff ${ }^{b}$, Eyal Grunebaumª ${ }^{a}$ Chaim M. \\ Roifman ${ }^{\mathrm{a}}$, and Ahmed Naqvi ${ }^{\mathrm{c}}$
}

\begin{abstract}
Introduction: The transcription factor Signal Transducer and Activator of Transcription 1 (STAT1) is a key element in many of the signalling cascades involved in immune system function. Different mutations in STAT1 are associated with heterogeneous clinical phenotypes that range from early fatality due to overwhelming infection to limited involvement of the mucus membrane with recurrent Candida infections. Multiple genes related to immune function have been associated with the development of hemophagocytic lymphohistiocytosis $(\mathrm{HLH})$, but the association between STAT1 mutation and HLH has not been described in detail.

Methods: We report the genetic background of a patient with chronic mucocutaneous candidiasis (CMC) as well as an unusual clinical course.

Results: In this study we describe a patient with a mutation in the STAT1 DNA-binding domain and a history of $\mathrm{CMC}$ who developed a refractory and fatal case of $\mathrm{HLH}$ despite having bone marrow transplantation.

Conclusion: We describe a patient with refractory and fatal HLH who was found to have a mutation in the DNAbinding domain of STAT1.
\end{abstract}

Statement of novelty: The association of chronic mucocutaneous candidiasis with HLH.

\section{Introduction}

The DNA-binding protein Signal Transducer and Activator of Transcription 1 (STAT1) is a member of a family of transcription factors that plays a major role in different and diverse functions of the cell. Following activation by interferon-gamma or interferon-alpha, STAT1 protein is phosphorylated and forms dimers. It then translocates into the nucleus, binds to DNA, and initiates its effector function (Darnell et al. 1994; Stark et al. 1998; Levy and Darnell 2002). Different genetic mutations in STAT1 resulting in different clinical phenotypes have been described (Dupuis et al. 2001, 2003; Chapgier et al. 2006a, 2006b). Patients with complete loss-of-function of the STAT1 protein usually die in childhood from overwhelming viral and mycobacterial infections (Dupuis et al. 2003). Other patients, who have the autosomal dominant STAT1 loss-of-function form, usually present with a predisposition to low pathogenic mycobacterial infections (Tsumura et al. 2012). Different mutations, mostly in the coiled-coiled domain, are believed to lead to gain of function of the a Division of Immunology and Allergy, The Hospital for Sick Children and The University of Toronto, Toronto, Canada; ${ }^{b}$ Department of Diagnostic Imaging, The Hospital for Sick Children and The University of Toronto, Toronto, Canada: ${ }^{c}$ Division of Haematology/Oncology Department of Pediatrics, The Hospital for Sick Children and The University of Toronto, Toronto, Canada

Submitted 28 May 2014

Accepted 29 May 2014

Available online 24 June 2014

LymphoSign Journal 1:87-95 (2014)

*Corresponding author: Yoram Faitelson/yoram.faitelson@sickkids.ca 
STAT1 protein and cause an autosomal dominant form of chronic mucocutaneous candidiasis (CMC) (Liu et al. 2011; van de Veerdonk et al. 2011). Recently, a severe and fatal form of combined immunodeficiency was found to be associated with a declining immunity during childhood, caused by predominantly de-novo mutations in the STAT1 DNA-binding domain (DBD) (Sharfe et al. 2014).

Hemophagocytic lymphohistiocytosis (HLH) is a rare, life-threatening inflammatory process that is characterized by uncontrolled activation of macrophages and histiocytes (Favara et al. 1997). Traditionally, HLH was divided into a genetic form (also known as the familial or primary type) and an acquired form (secondary HLH) (Writing Group of the Histiocyte Society 1987; Henter et al. 1991).

The genetic form usually presents in a young infant with parental consanguinity or a history of other affected family members. Patients in this group have a genetic defect in genes that are responsible for the cytotoxic function of T cells and NK cells. Most commonly, mutations in the gene PFR1 that encodes for Perforin1, are detected in this group of patients; however, other genes, such as UNC13D and STX11 that encode for cytolytic granule trafficking and exocytosis may also be associated with the aberrant inflammation (Jordan et al. 2011). Although some of the primary immunodeficiency disorders that are associated with HLH have abnormal cytotoxic function of $\mathrm{T}$ cells and NK cells (for example Chédiak-Higashi syndrome and Griscelli syndrome type 2) others such as Wiskott-Aldrich and DiGeorge syndrome do not, and the mechanism leading to HLH in these conditions is not fully understood (Introne et al. 1999; Ménasché et al. 2000; Cesaro et al. 2003; Pasic et al. 2003).

In contrast to the genetic form of HLH, the acquired forms seem not to be associated with a known genetic abnormality or immunodeficiency syndrome. As in some of the genetic forms, the pathogenesis is not completely understood, and it seems that the disease appears in association with infection, malignancy, rheumatic conditions, metabolic disorders, or as a consequence of drug toxicity (Henter et al. 1991; Janka et al. 1998). Nevertheless, it is conceivable that modifier genes may predispose individuals to developing secondary HLH. The symptoms and signs of HLH are nonspecific; fever, hepatosplenomegaly, lymphadenopathy, cytopenia, morbiliformic rash, and in some cases involvement of the central nervous system (CNS) with seizures or encephalopathy (Henter et al. 2007).

Without treatment, the prognosis of HLH is poor, with less than 5\% survival 1 year post diagnosis (Janka 1983). Even with appropriate treatment, the mortality rate can be as high as $45 \%$ (Henter et al. 2002). The main goal of the treatment is to suppress the exaggerated activation of the immune system with immunosuppressive agents such as dexamethasone, etoposide, and cyclosporine, and when needed and indicated a bone marrow transplantation (Henter et al. 2002).

We report here an occurrence of fatal $\mathrm{HLH}$ in a patient with CMC due to STAT1 deficiency.

\section{Methods}

\section{Flow cytometry}

Peripheral blood mononuclear cells were obtained by Ficoll-Hypaque density gradient centrifugation, and surface phenotypes were determined by flow cytometry on a Coulter EPICS V flow cytometer (Beckman Coulter, Brea, Calif.), with a single argon laser, which analyzes up to 3 colours simultaneously. Single colour and (or) isotype antibody controls were both used for multicolour staining.

\section{Proliferation assay}

Lymphocyte proliferative responses to mitogens (including phytohemagglutinin and anti-CD3 antibodies) and to a panel of recall antigens (including Candida, tetanus, Herpes zoster, and cytomegalovirus) were determined by thymidine incorporation. All assays were performed in triplicate and were compared with simultaneously stimulated random normal controls.

\section{DNA sequencing}

Genomic DNA was extracted from peripheral blood lymphocytes using the Geneaid Genomic DNA Mini Kit. Genomic DNA was amplified by polymerase chain reaction (PCR) with specific primers for exons 1-23 of the coding sequence of STAT1 (NM_007315.3) (available upon request). Exons and their flanking intronic regions were sequenced with the GenomeLab Dye Terminator Cycle Sequencing Quick Start Kit (Beckman Coulter) and analyzed on a CEQ 8000 Genetic Analysis System (Beckman Coulter). 


\section{Results}

\section{Case presentation}

The patient, a female of nonconsanguineous East Indian origin, presented at 5 months of age with recurrent episodes of skin infection and persistent diaper rash and oral thrush. Her past medical history was unremarkable and her family history was negative for immunodeficiency, malignancy, or autoimmune disorders. The laboratory findings were unremarkable with normal levels of leukocytes and immunoglobulins (Table 1). She responded to Nystatin but continued to have periodic episodes of oral thrush. At the age of 3 years she was diagnosed with hypothyroidism and began suffering repeated episodes of pneumonia as well as asthma. At the age of 9 years she was found to have oral thrush and herpetic vesicles on her chest without hepatosplenomegaly or lymphadenopathy. She responded well to treatment with oral Fluconazole and Acyclovir. She subsequently developed Coombs-positive hemolytic anemia.

\section{Evaluation of the immune system}

Evaluation of the immune system revealed normal numbers of circulating white blood cells and lymphocytes. Flow cytometry analysis showed a steady decline of $\mathrm{CD}^{+}$ circulating lymphocytes over time. Predominantly $\mathrm{CD} 4^{+}$ $\mathrm{T}$ cells diminished over time down to 440 cells/ $\mu \mathrm{L}$. In addition, the number of NK cells was also declining to 77 cells $/ \mu \mathrm{L}$ at the age of 10 years. These changes are consistent with the recently documented decline in immunity in patients with STAT1 mutations in the DBD (Sharfe et al. 2014).

The number of circulating B cells appears to have been normal with little decline. Serum immunoglobulin levels increased over time particularly for IgG and IgA (Table 1), and specific antibodies to vaccination appeared to be preserved. In-vitro response to mitogens and antigens were still preserved in this patient.

\section{Genetic analysis}

Genetic analysis of the STAT1 gene (Figure 1) revealed a mutation in the DBD of the molecule. The mutation was a de novo mutation, as it was not present in the parents or in the brother of the patient.

\section{Course of HLH}

The patient presented at the age of 10 years in the emergency department with a high fever, cough, and pancytopenia. An abdominal ultrasound and abdominal

Table 1: Evaluation of immunity over time.

\begin{tabular}{|c|c|c|c|c|}
\hline & \multicolumn{3}{|c|}{ Age in years } & \multirow[b]{2}{*}{ Reference values } \\
\hline & 1.5 & 9 & 10 & \\
\hline White blood cells & 9.1 & 7.8 & 6.2 & $4-10 \times 10^{9} / \mathrm{L}$ \\
\hline \multicolumn{5}{|l|}{ Markers } \\
\hline CD3 & 1742 & 1128 & 1061 & 800-3500 cell/ $\mu \mathrm{L}$ \\
\hline CD4 & 939 & 520 & 440 & 400-2100 cell/ $/ \mu \mathrm{L}$ \\
\hline CD8 & 634 & 456 & 504 & 200-1200 cell/ $\mu \mathrm{L}$ \\
\hline CD20/19 & 1968 & 486 & 837 & 200-600 cell/ $\mu \mathrm{L}$ \\
\hline CD56 & 160 & 160 & 77 & 70-1200 cell/ $\mu \mathrm{L}$ \\
\hline \multicolumn{5}{|l|}{ Immunoglobulins } \\
\hline $\lg G$ & 11 & 16.5 & 12.4 & $6.6-15.3 \mathrm{~g} / \mathrm{L}$ \\
\hline $\operatorname{lgM}$ & 1 & 1.3 & 1.1 & $0.5-1.9 \mathrm{~g} / \mathrm{L}$ \\
\hline $\lg A$ & 0.7 & 3 & 4.6 & $0.5-2.2 \mathrm{~g} / \mathrm{L}$ \\
\hline $\lg E$ & 27 & & & $<60 \mathrm{IU} / \mathrm{mL}$ \\
\hline \multicolumn{5}{|l|}{ Specific antibodies } \\
\hline Tetanus & $1.96 \mathrm{IU} / \mathrm{mL}$ & $0.26 \mathrm{IU} / \mathrm{mL}$ & $0.19 \mathrm{IU} / \mathrm{mL}$ & $>0.01$ \\
\hline Mumps & & Positive (44 RU/L) & Borderline & Positive \\
\hline Measles & & Positive (495 IU/L) & Positive (465 IU/L) & Positive \\
\hline Rubella & & Positive (199 IU/L) & Positive (200 IU/L) & Positive \\
\hline Varicella & & Negative & Positive & Positive \\
\hline Iseohemmagglutinin & & $1: 32$ & & $1: 8$ \\
\hline
\end{tabular}


STAT1

WT
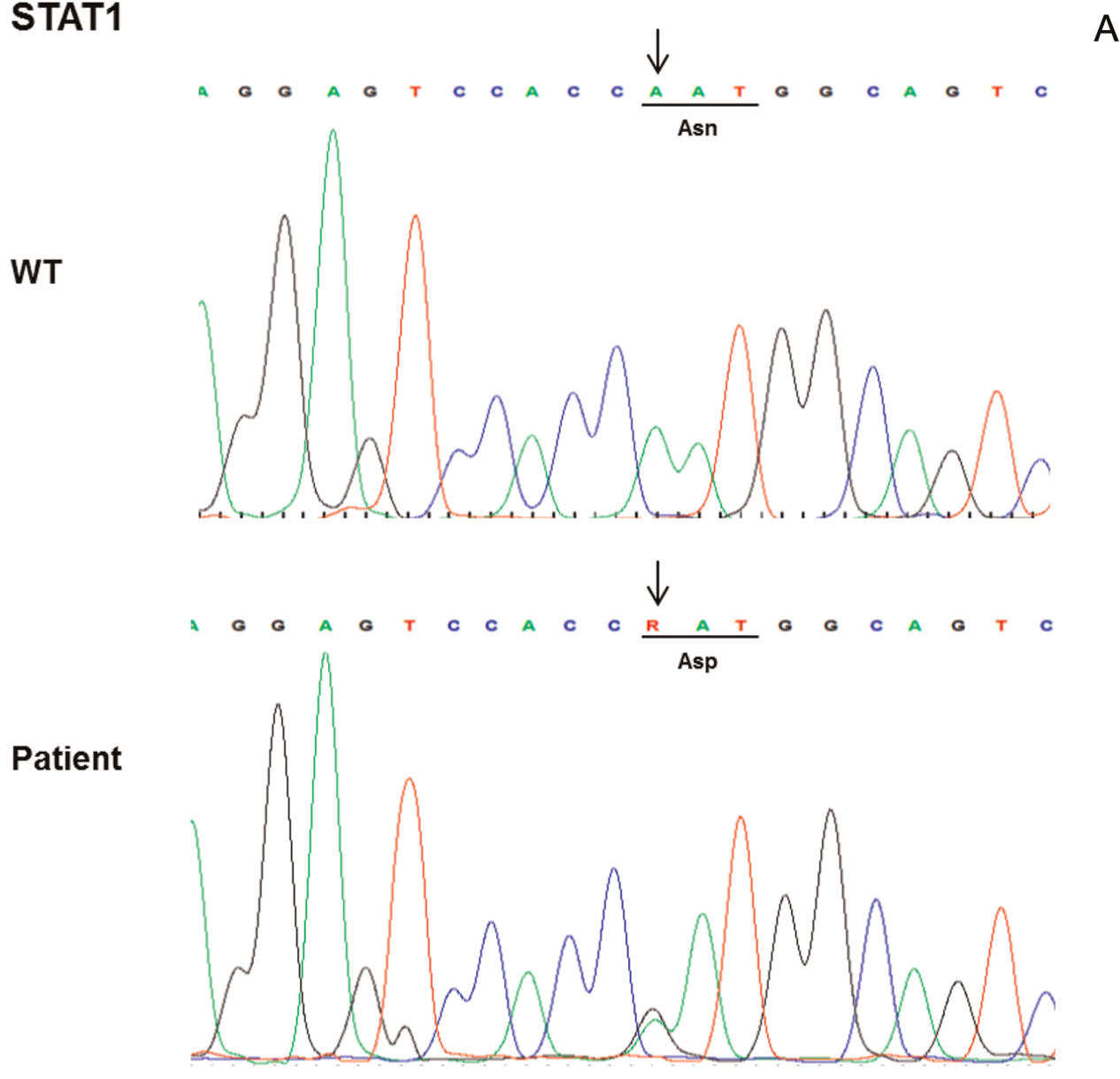

B

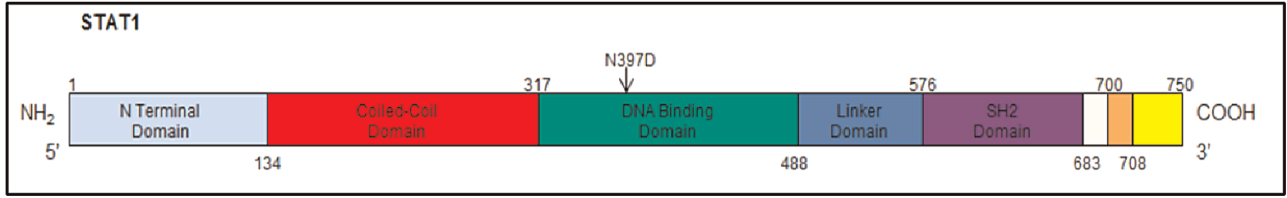

Figure 1: Electropherogram showing the wild type vs patient sequence with heterozygous mutation c.(1189A > G)];(=) in STAT1 (NM_007315.3) resulting in amino acid substitution p.(Asn397Asp);(=)(A). Human STAT1 showing the $\mathrm{N}$ terminal domain, coiled-coil domain, DNA-binding domain, linker domain, $\mathrm{SH} 2$ domain, tail segment domain, and transactivation domain, their boundaries and the location of the N397D mutation.

CT (taken later), showed findings suggestive of a microabscess in the kidneys and spleen. An extensive infection workup that included blood cultures, serology, and PCR testing for bacteria, mycobacteria, fungi, and different viruses (Herpes family, respiratory viruses, and parvovirus) identified Epstein-Barr Virus viremia with a viral load of 1127 copies/mL in the blood (but not in the plasma). In addition, Herpes zoster virus was isolated from a skin vesicle.

As the fever continued, an initial blood work was sent to assess for HLH. The diagnostic criteria for HLH, according to the HLH-2004 protocol by the Histiocyte
Society, include a molecular diagnosis consistent with HLH or 5 out of 8 clinical and laboratory criteria as described in Table 2 (Henter et al. 2007).

Although the initial blood work didn't fully support the diagnosis of HLH, the repeated blood work that was done on the second week of her admission confirmed the diagnosis (Table 3).

The patient was treated with broad spectrum antibiotics, anti-fungal, and anti-viral medications. After HLH was diagnosed, she started treatment with dexamethasone but showed only partial response. A day following 
Table 2: Criteria for the diagnosis of HLH.

\begin{tabular}{l}
\hline Clinical criteria \\
Fever \\
Splenomegaly \\
Laboratory criteria \\
Cytopenia (affecting $>2$ of 3 lineage in peripheral blood) \\
Hypertriglyceridemia or hypofibrinogenemia \\
Low or absent NK cell activity \\
Hyperferritinemia $>500 \mu g r a m / L$ \\
Increased levels of sCD $25>2400 \mathrm{U} / \mathrm{mL}$ \\
Histopathological criteria \\
Hemophagocytosis in the bone marrow, spleen, or lymph \\
nodes \\
No evidence of malignancy
\end{tabular}

initial steroid treatment she developed seizures and her brain MRI showed bilateral multifocal abnormal signals in the cortex and subcortical white matter associated with leptomeningeal enhancement, findings that are consistent but not specific to CNS involvement of HLH (Figure 2).

Despite receiving appropriate antibiotic treatment, she did not improve and continued to be febrile with increased laboratory markers of HLH. The treatment for HLH was escalated to include etoposide, cyclosporine, and intrathecal methotrexate similar to the HLH2004 protocol recommendation. The patient had a temporary response to the treatment as fevers subsided and repeated head imaging showed resolution of the abnormal MRI findings (Figures 3 and 4). However, she failed to get into full remission as her laboratory markers persistently showed cytopenia, increased ferritin, and elevated sCD25 levels.

After 8 weeks of treatment and following the HLH2004 protocol recommendation for severe cases of HLH, a bone marrow transplant (BMT) was performed using an HLA matched unrelated donor in the absence of a matched sibling. The patient received a full myeloablative conditioning that included Busulfan $(3.6 \mathrm{mg} / \mathrm{kg})$ on days -8 to -5 , etoposide $(30 \mathrm{mg} / \mathrm{kg} /$ dose $)$ on day -4 , and cyclophosphamide $(60 \mathrm{mg} / \mathrm{kg})$ on days -3 and -2 . For graft versus host disease prophylaxis she received steroids, cyclosporine, and methotrexate. The patient fully engrafted on day +8 with $100 \%$ chimerism, but she spiked a fever and once again suffered seizures within a week of transplant. A repeat MRI of her head again showed multiple cortical and white matter lesions, similar to the lesions described in Figure 2. The laboratory markers for HLH, which are sCD25, sCD163, and ferritin peaked to 4063 $\mathrm{U} / \mathrm{mL}, 8178 \mathrm{ng} / \mathrm{mL}$, and $949510 \mu \mathrm{g} / \mathrm{L}$, respectively. She subsequently developed severe complications including gastrointestinal bleeding, pulmonary hemorrhage, toxic epidermal necrosis, and renal failure. In addition, alemtuzumab was added to the regimen with no response. The patient deteriorated gradually until her death from multi-organ failure.

\section{Discussion}

In the last few years, different mutations in the STAT1 gene have been reported (Liu et al. 2011; van de

Table 3: Markers of HLH over time.

\begin{tabular}{|c|c|c|c|c|}
\hline Marker & Initial workup & Workup at diagnosis & $\begin{array}{l}\text { Workup post bone marrow } \\
\text { transplantation }\end{array}$ & $\begin{array}{l}\text { Reference } \\
\text { values }\end{array}$ \\
\hline White blood cells & 0.9 & 1.5 & 5.7 & $4-10 \times 10^{9} / \mathrm{L}$ \\
\hline Hemoglobin & 90 & 82 & $97^{*}$ & $120-160 \mathrm{~g} / \mathrm{L}$ \\
\hline Platelets & 78 & 74 & $144^{*}$ & $150-400 \times 10^{9} / \mathrm{L}$ \\
\hline Ferritin & 3156 & 41950 & 949510 & 30-177 $\mu \mathrm{g} / \mathrm{L}$ \\
\hline Triglycerides & 3.1 & 4.2 & 16 & $0.4-1.3 \mathrm{mmol} / \mathrm{L}$ \\
\hline Fibrinogen & 1.5 & 1.8 & 3.5 & $1.9-4.3 \mathrm{~g} / \mathrm{L}$ \\
\hline slL2 receptor (sCD25) & 1770 & 3101 & 4063 & 340-1500 U/mL \\
\hline Bone marrow aspiration & $\begin{array}{c}\text { No hemophagocytosis } \\
\text { present }\end{array}$ & $\begin{array}{c}\text { Hemophagocytosis } \\
\text { present }\end{array}$ & - & - \\
\hline $\begin{array}{l}\text { Perforin expression by flow } \\
\text { cytometery }\end{array}$ & Normal & - & - & - \\
\hline Perforin gene sequencing & Normal & - & - & - \\
\hline $\begin{array}{l}\text { NK cells degranulation } \\
\text { assay }\end{array}$ & Normal & - & - & - \\
\hline
\end{tabular}

${ }^{*}$ Post blood/platelets transfusion. 


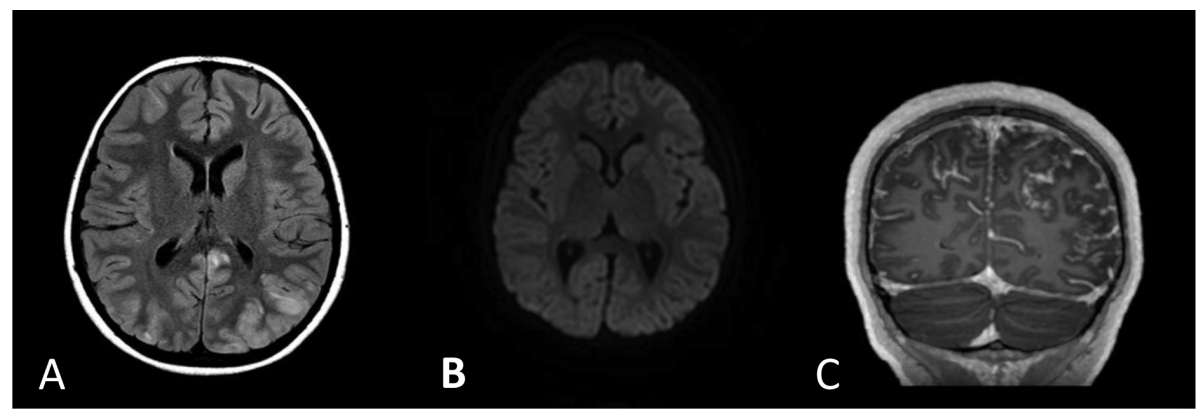

Figure 2: Axial fluid attenuated inversion recovery $(A)$, axial diffusion weighted image (B), and contrast-enhanced coronal T1 images (C) show an abnormal signal in the cortex and subjacent white matter bilaterally. Subtle diffusion restriction is seen within these abnormal areas. In addition, there is enhancement in the leptomeninges, which is more pronounced in the sulci associated with those areas of an abnormal signal.

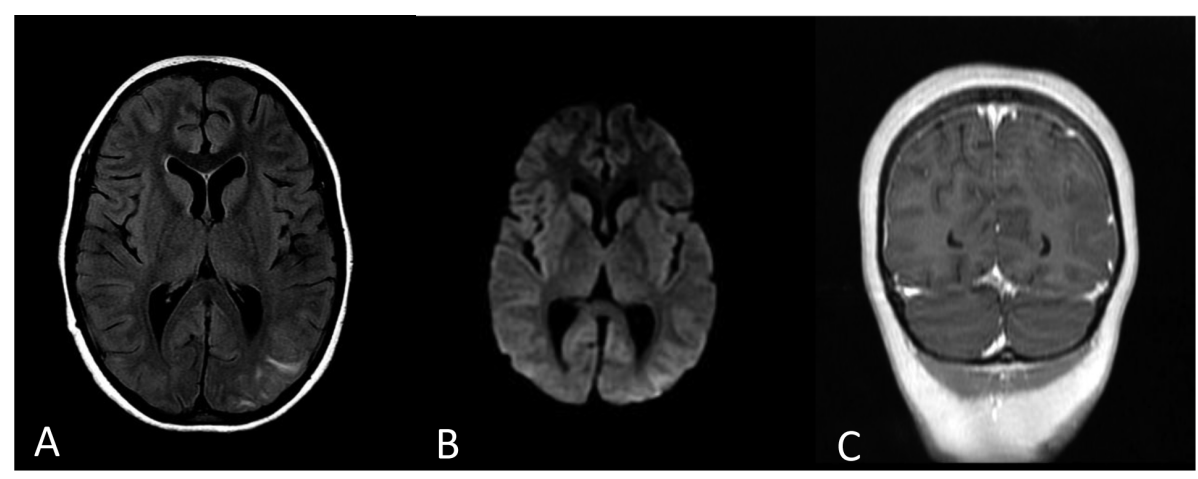

Figure 3: Axial fluid attenuated inversion recovery $(A)$, axial diffusion weighted image (B), and contrast enhanced coronal T1 images (C) on the follow-up MRI show that the previously noted signal changes improved significantly with residual abnormality in the left parietal and occipital parietal lobes. No definite diffusion restriction is noted. The post-gadolinium image shows that the previously noted leptomeningeal enhancement is no longer visualized.

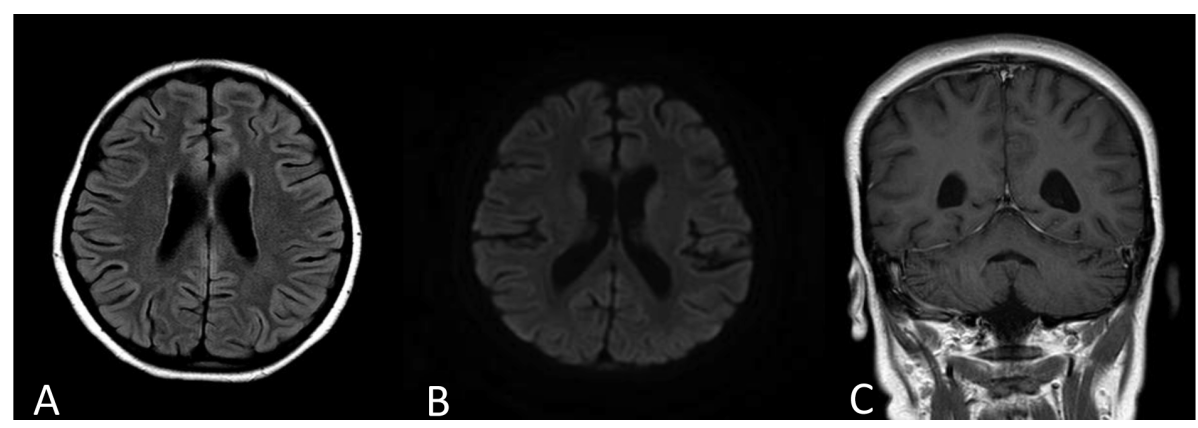

Figure 4: Axial fluid attenuated inversion recovery $(A)$, axial diffusion weighted image (B), and contrast enhanced coronal T1 images (C) on another follow-up MRI a week after the MRI shown in Figure 3. There is further improvement with complete resolution of the abnormal cerebral signal changes and the abnormal leptomeningeal enhancement. The ventricles and pericerebral spaces are prominent bilaterally and have mildly increased in size compared with the previous studies with no midline shift. These findings are in keeping with volume loss. 
Veerdonk et al. 2011; Tsumura et al. 2012). Monoallelic mutations in the DBD of STAT1 seem to cause a severe and frequently fatal immunodeficiency (Sharfe et al. 2014). In this study we described a mutation in the DBD of the molecule. The fact that these mutations are de novo mutations, support the hypothesis that changes in the DBD of the STAT1 gene are lethal at a young age before the carrier has a chance to produce offspring. The patient we described here had clinical symptoms of CMC and declining immunity that specifically displayed a decline in $\mathrm{CD}^{+}{ }^{+} \mathrm{T}$ cells and NK cells. The diminished number and function of NK cells were previously reported to be associated with HLH. In this case, it is also conceivable that the decline in NK cell numbers underscored at least in part the development of HLH, although the NK cell degranulation assay was normal.

CNS involvement is common in HLH patients, and symptoms can range from abnormal findings in the cerebrospinal fluid to altered mental status, seizures, and coma. Active HLH, infection, and posterior reversible encephalopathy syndrome (PRES) are in the differential diagnosis in HLH patients with CNS involvement (Haddad et al. 1997; Goo and Weon 2007; Horne et al. 2008; Lee et al. 2013).

The overall survival of children with HLH who were treated with the HLH-94 protocol is around 55\% and two-thirds of those who survived underwent BMT. It appears that survival after BMT in HLH cases is fair, regardless of whether a HLA matched sibling or an unrelated match donor are used (Henter et al. 2007). Although there are some reports that support reduced intensity over full myeloablative conditioning (Cooper et al. 2006; Marsh et al. 2010), at present there is insufficient evidence to support the use of one protocol over another. Out of the few reports of BMT in patients with STAT1 mutation, only 2 patients have been reported with long-term survival after receiving a BMT from a match sibling donor (Deeg et al. 1986; Hoh et al. 1996), whereas 2 other patients died after the procedure (Aldave et al. 2013).

In conclusion, we have shown an association between a monoallelic STAT1 mutation and a severe and refractory case of HLH. A thorough immunologic workup that includes STAT1 genetic analysis is needed in severe and refractory cases of HLH to identify those who have this uncommon genetic abnormality. More studies are in order to define optimal treatment options for patients with STAT1 mutation and HLH.

\section{REFERENCES}

Aldave, J.C., Cachay, E., Núñez, L., Chunga, A., Murillo, S., and Cypowyj, S., et al. 2013. A 1-year-old girl with a gain-of-function STAT1 mutation treated with hematopoietic stem cell transplantation. J. Clin. Immunol. 33(8):1273-1275. PMID: 24105462. doi: 10.1007/ s10875-013-9947-5.

Cesaro, S., Messina, C., Sainati, L., Danesino, C., and Aricò, M. 2003. Del 22Q11.2 and hemophagocytic lymphohistiocytosis: a non-random association. Am. J. Med. Genet. A. 116A(2):208-209. PMID: 12494446. doi: 10.1002/ajmg.a.10122.

Chapgier, A., Boisson-Dupuis, S., Jouanguy, E., Vogt, G., Feinberg, J., and Prochnicka-Chalufour, A., et al. 2006a. Novel STAT1 alleles in otherwise healthy patients with mycobacterial disease. PLoS Genet. 2(8): e131. PMID: 16934001. doi: 10.1371/journal.pgen. 0020131.

Chapgier, A., Wynn, R.F., Jouanguy, E., Filipe-Santos, O., Zhang, S., and Feinberg, J., et al. 2006b. Human complete Stat-1 deficiency is associated with defective type I and II IFN responses in vitro but immunity to some low virulence viruses in vivo. J. Immunol. 176(8):5078-5083. PMID: 16585605. doi: 10.4049/ jimmunol.176.8.5078.

Cooper, N., Rao, K., Gilmour, K., Hadad, L., Adams, S., and Cale, C., et al. 2006. Stem cell transplantation with reduced-intensity conditioning for hemophagocytic lymphohistiocytosis. Blood. 107(3):1233-1236. PMID: 16219800. doi: 10.1182/blood-2005-05-1819.

Darnell, J.E. Jr., Kerr, I.M., and Stark, G.R. 1994. Jak TAT pathways and transcriptional activation in response to IFNs and other extracellular signaling proteins. Science. 264(5164):1415-1421. PMID: 8197455. doi: 10.1126/science.8197455.

Deeg, H.J., Lum, L.G., Sanders, J., Levy, G.J., Sullivan, K. M., and Beatty, P., et al. 1986. Severe aplastic anemia associated with chronic mucocutaneous candidiasis. Immunologicand hematologicreconstitution after allogeneic bone marrow transplantation. Transplantation. 41(5):583-586. PMID: 3518164. doi: 10.1097/ 00007890-198605000-00006.

Dupuis, S., Dargemont, C., Fieschi, C., Thomassin, N., Rosenzweig, S., and Harris, J., et al. 2001. Impairment of mycobacterial but not viral immunity by a germline human STAT1 mutation. Science. 293(5528): 300-303. PMID: 11452125. doi: 10.1126/science. 1061154. 
Dupuis, S., Jouanguy, E., Al-Hajjar, S., Fieschi, C., AlMohsen, I.Z., and Al-Jumaah, S., et al. 2003. Impaired response to interferon-alpha/beta and lethal viral disease in human STAT1 deficiency. Nat. Genet. 33(3): 388-391. PMID: 12590259. doi: 10.1038/ng1097.

Favara, B.E., Feller, A.C., Pauli, M., Jaffe, E.S., Weiss, L. M., and Arico, M., et al. 1997. Contemporary classification of histiocytic disorders. The WHO Committee On Histiocytic/Reticulum Cell Proliferations. Reclassification Working Group of the Histiocyte Society. Med. Pediatr. Oncol. 29(3):157-166. doi: 10.1002/(SICI) 1096-911X(199709)29:3<157::AID-MPO1>3.0.CO;2-C.

Goo, H.W., and Weon, Y.C. 2007. A spectrum of neuroradiological findings in children with haemophagocytic lymphohistiocytosis. Pediatr. Radiol. 37(11): 1110-1117. PMID: 17846757. doi: 10.1007/s00247007-0569-z.

Haddad, E., Sulis, M.L., Jabado, N., Blanche, S., Fischer, A., and Tardieu, M. 1997. Frequency and severity of central nervous system lesions in hemophagocytic lymphohistiocytosis. Blood. 89(3): 794-800. PMID: 9028310.

Henter, J.I., Elinder, G., and Ost, A. 1991. Diagnostic guidelines for hemophagocytic lymphohistiocytosis. The FHL Study Group of the Histiocyte Society. Semin. Oncol. 18(1):29-33. PMID: 1992521.

Henter, J.I., Horne, A., Aricó, M., Egeler, R.M., Filipovich, A.H., and Imashuku, S., et al. 2007. HLH-2004: diagnostic and therapeutic guidelines for hemophagocytic lymphohistiocytosis. Pediatr. Blood Cancer. 48(2): 124-1231. PMID: 16937360. doi: 10.1002/pbc.21039.

Henter, J.I., Samuelsson-Horne, A., Aricò, M., Egeler, R. M., Elinder, G., and Filipovich, A.H., et al. 2002. Treatment of hemophagocytic lymphohistiocytosis with HLH-94 immunochemotherapy and bone marrow transplantation. Blood. 100(7):2367-2373. PMID: 12239144. doi: 10.1182/blood-2002-01-0172.

Hoh, M.C., Lin, H.P., Chan, L.L., and Lam, S.K. 1996. Successful allogeneic bone marrow transplantation in severe chronic mucocutaneous candidiasis syndrome. Bone Marrow Transplant. 18(4):797-800. PMID: 8899198.

Horne, A., Trottestam, H., Aricò, M., Egeler, R.M., Filipovich, A.H., and Gadner, H., et al. 2008. Frequency and spectrum of central nervous system involvement in 193 children with haemophagocytic lymphohistiocytosis. Br. J. Haematol. 140(3):327-335. PMID: 18076710. doi: 10.1111/j.1365-2141.2007.06922.x.

Introne, W., Boissy, R.E., and Gahl, W.A. 1999. Clinical, molecular, and cell biological aspects of ChediakHigashi syndrome. Mol. Genet. Metab. 68(2):283303. PMID: 10527680. doi: 10.1006/mgme.1999.2927.
Janka, G.E. 1983. Familial hemophagocytic lymphohistiocytosis. Eur. J. Pediatr. 140(3):221-230. PMID: 6354720. doi: 10.1007/BF00443367.

Janka, G., Imashuku, S., Elinder, G., Schneider, M., and Henter, J.I. 1998. Infection- and malignancyassociated hemophagocytic syndromes. Secondary hemophagocytic lymphohistiocytosis. Hematol. Oncol. Clin. North Am. 12(2):435-444. doi: 10.1016/S08898588(05)70521-9.

Jordan, M.B., Allen, C.E., Weitzman, S., Filipovich, A.H., and McClain, K.L. 2011. How I treat hemophagocytic lymphohistiocytosis. Blood. 118(15):4041-4052. PMID: 21828139. doi: 10.1182/blood-2011-03-278127.

Lee, G., Lee, S.E., Ryu, K.H., and Yoo, E.S., et al. 2013. Posterior reversible encephalopathy syndrome in pediatric patients undergoing treatment for hemophagocytic lymphohistiocytosis: clinical outcomes and putative risk factors. Blood Res. 48(4): 258-265. PMID: 24466550. doi: 10.5045/br.2013.48. 4.258 .

Levy, D.E., and Darnell, J.E. Jr.. 2002. Stats: transcriptional control and biological impact. Nat. Rev. Mol. Cell. Biol. 3(9):651-662. PMID: 12209125. doi: 10.1038/nrm909.

Liu, L., Okada, S., Kong, X.F., Kreins, A.Y., Cypowyj, S., and Abhyankar, A., et al. 2011. Gain-of-function human STAT1 mutations impair IL-17 immunity and underlie chronic mucocutaneous candidiasis. J. Exp. Med. 208(8):1635-1648. PMID: 21727188. doi: 10.1084/jem.20110958.

Marsh, R.A., Vaughn, G., Kim, M.O., Li, D., Jodele, S., and Joshi, S., et al. 2010. Reduced-intensity conditioning significantly improves survival of patients with hemophagocytic lymphohistiocytosis undergoing allogeneic hematopoietic cell transplantation. Blood. 116(26):5824-5831. PMID: 20855862. doi: 10.1182/ blood-2010-04-282392.

Ménasché, G., Pastural, E., Feldmann, J., Certain, S., Ersoy, F., and Dupuis, S., et al. 2000. Mutations in RAB27A cause Griscelli syndrome associated with haemophagocytic syndrome. Nat. Genet. 25(2): 173-176. PMID: 10835631. doi: 10.1038/76024.

Pasic, S., Micic, D., and Kuzmanovic, M. 2003. EpsteinBarr virus-associated haemophagocytic lymphohistiocytosis in Wiskott-Aldrich syndrome. Acta. Paediatr. 92(7):859-861. PMID: 12892170. doi: 10.1111/ j.1651-2227.2003.tb02548.x.

Sharfe, N., Nahum, A., Newell, A., Dadi, H., Ngan, B., and Pereira, S.L., et al. 2014. Fatal combined immunodeficiency associated with heterozygous mutation in STAT1. J. Allergy. Clin. Immunol. 133(3):807-817. PMID: 24239102. doi: 10.1016/j.jaci.2013.09.032. 
Stark, G.R., Kerr, I.M., Williams, B.R., Silverman, R.H., and Schreiber, R.D. 1998. How cells respond to interferons. Annu. Rev. Biochem. 67:227-264. PMID: 9759489. doi: 10.1146/annurev.biochem.67.1.227.

Tsumura, M., Okada, S., Sakai, H., Yasunaga, S., Ohtsubo, M., and Murata, T., et al. 2012. Dominantnegative STAT1 SH2 domain mutations in unrelated patients with Mendelian susceptibility to mycobacterial disease. Hum. Mutat. 33(9):1377-1387. PMID: 2257 3496. doi: 10.1002/humu.22113. van de Veerdonk, F.L., Plantinga, T.S., Hoischen, A., Smeekens, S.P., Joosten, L.A., and Gilissen, C., et al. 2011. STAT1 mutations in autosomal dominant chronic mucocutaneous candidiasis. N. Engl. J. Med. 365(1):54-61. PMID: 21714643.

Writing Group of the Histiocyte Society. 1987. Histiocytosis syndromes in children. Lancet. 1(8526):208-209. PMID: 2880029. 